\title{
THE INTERRELATIONSHIPS OF CHILD UNDER-NUTRITION, ECOLOGICAL AND MATERNAL FACTORS: A CASE STUDY OF PAKISTAN BY USING COMPOSITE INDEX OF ANTHROPOMETRIC FAILURE
}

\author{
ASIF, M. A. ${ }^{1 *}-$ AKBAR, M. ${ }^{1}-$ NOOR, F. $^{1}-$ SHERWANI, R. A. K. ${ }^{2}-$ FAROOQ, M. $^{3}$ \\ ${ }^{1}$ Department of Mathematics and Statistics, Faculty of Basic and Applied Sciences, \\ International Islamic University, 44000 Islamabad, Pakistan \\ ${ }^{2}$ College of Statistical and Actuarial Sciences, University of the Punjab, Lahore, Pakistan \\ ${ }^{3}$ Department of Statistics, University of Gujrat, Gujrat, Pakistan \\ *Corresponding author \\ e-mail: atta.msst18@iiu.edu.pk \\ (Received 23 $3^{\text {rd }}$ May 2019; accepted $28^{\text {th }}$ Aug 2019)
}

\begin{abstract}
Under-nutrition is a serious health problem of developing countries, including Pakistan. Despite the implementation of a number of health strategies for the vulnerable population (especially children), the issue is still emerging and needs further investigation. The aim of this study was to investigate the role of various ecological and maternal factors responsible of children's nutritional health variations. By using Pakistan Demographic and Health Survey (PDHS) data, maternal factors were assessed as important factors of child under-nutrition. Multinomial nested logit regression and classification tree analysis were performed. A total of 1870 children of age $<5$ years were included in the analysis and out of these $50.1 \%$ fall in the composite index of anthropometric failure (CIAF). Maternal education, mother's body mass index (BMI) and working status were among the significant factors while decision making autonomy remain insignificant. Maternal factors have significant impact on child health and use of CIAF as a measure of nutritional status is recommended for policy makers because of its capability to estimate the overall burden of under-nutrition.
\end{abstract}

Keywords: child health, demographic and health survey, nested logit regression, wealth status, classification tree

\section{Introduction}

Role of population's nutritional status is important in socio-economic development of a country. Adequate nutrition level for children's growth and development is imperative. Early years of life are of huge significance for mental as well as physical growth of a child. However, this age is regularly set apart by micronutrient inadequacies that meddle with ideal development. Moreover, children's of this age are powerless against the irresistible sicknesses such as diarrhea and acute respiratory infections (Final Report PDHS, 2012-2013). It is, therefore, considered as one of the important components of Sustainable Development Goals (SDGs) adopted by UN in 2015. A malnourished child is more likely to die from common illnesses such as malaria, measles, diarrhea and pneumonia (Chowdhury et al., 2016). Poor nutritional status increases the risk of infection, morbidity and mortality along with decline of mental development during the early years of child-hood (Endris et al., 2017). Hence, children are more vulnerable to under-nutrition. United Nations statistics show that 155 million children were stunted, 41 million were overweight and 52 million were wasted in 2016 (WHO, 2017). About $50 \%$ of these children live in the three south Asian countries, i.e. 
Pakistan, India and Bangladesh (Achadi et al., 2016), and under-nutrition is one of the major challenges in these countries. Best nutritional status of the children is one of best indicators of their well-being (Poda et al., 2017). A bunch of factors, which can affect child under-nutrition, are considered by various studies. These factors comprise of health care services, maternal literacy, wealth status, maternal decision making autonomy etc. (Amugsi et al., 2014; Debnath and Bhattacharjee, 2016).

Maternal factors are considered as the most important factors for children's health (Vikram et al., 2012). Existing literature reveals that improved maternal education can positively affect child's health (Arooj et al., 2013). Numerous studies considered the role of maternal factors as well as other socio-economic and demographic factors for improvement of child under-nutrition in middle and low income countries (Poda et al., 2017; Debnath and Bhattacharjee, 2016; Krishna et al., 2017; Sarma et al., 2017; Rakotomanana et al., 2017; Altare et al., 2016; Alemayeha et al., 2015; Senbanjo et al., 2013; Anekwe and Kumar, 2012; Pradhan, 2010). Gender of the child, child, size at birth, maternal education, mother's BMI, wealth status, dietary diversity, mother's decision making autonomy and vaccination were among the most important factors affecting child under-nutrition in the above mention studies. However, some studies showed insignificant relationship between child under-nutrition and mother's BMI, mother's education, fathers educations as well as wealth status of household (Rahman, 2016; Sharma and Kader, 2013; Maïga, 2013).

Pakistan, with sixth largest country by population, is ranked at 124 out of 132 countries with $45 \%$ stunted children and 106 out of 130 countries with $11 \%$ prevalence of wasting among children (Raju and D'Souza, 2017). According to global nutritin report, only $0.7 \%$ of government expenditure is allocated for nutrition-sensitive interventions, which is less than other countries in the region such as Nepal and Bangladesh, with $3.1 \%$ and $2.1 \%$ allocations respectively (Achadi et al., 2016). It reveals worst conditions of child under-nutrition in Pakistan and government negligence. A number of studies have considered these issues and discuss various causes of child under-nutrition. For example Tariq et al. (2018) identified that mother's BMI, rural residence, parental education, poverty and type of toilet facility were the associated factors of child under-nutrition. A study explored that maternal health and child health were among the most significant factors associated with stunting and wasting (Achakzai and Khan, 2016). Wealth status was considered as important factor of child under-nutrition while maternal education was declared insignificant by a study (Khan and Raza, 2014). However, Mahmood et al. (2016) revealed that maternal education was a significant factor to improve child under-nutrition in Pakistan.

Most of the aforementioned studies applied logistic framework and child undernutrition was measured through commonly used anthropometric indices named stunting, wasting and underweight. These measures however, describe different dimensions of under-nutrition and are overlapping. For instance, underweight is the composition of both wasting and stunting, but does not make a separation between them (Fentahun et al., 2016). Moreover, none of the conventional indices has capability to provide a comprehensive measure of under-nutrition in the population (Khan and Raza, 2014). Therefore, the use of single indicator, that must be able to capture the magnitude of nutritional status and identify the susceptible part in the population, is needed. Peter Svedberg, a development economist, proposed an important measure of child nutrition, known as composite index of anthropometric failure (CIAF) (Svedberg, 2000). A number of recent studies in the literature has used this proposed indicator for different 
countries (Endris et al., 2017; Khan and Raza, 2014; Fentahun et al., 2016; Sen and Mondal, 2012; Ejaz and Azid, 2011; Das and Bose, 2011) and they have recommended this indicator as an alternative measure of under-nutrition.

Conventional measures of under-nutrition (stunting, wasting and underweight) are commonly used in the existing studies for Pakistan (Tariq et al., 2018; Arif et al., 2011; Mushtaq et al., 2011). Moreover, neither of these studies focused on ecological and maternal factors, solely, nor the exposure variables as well as control variables were selected under UNICEF conceptual framework to analyze child under-nutrition. Keeping in view these gaps the specific objectives of this study were: first, to check the role/importance of maternal factors, selected under UNICEF conceptual framework, on child under-nutrition. Second, to consider CIAF as an alternative measure of child under-nutrition instead of conventional measures using nationwide community health survey data.

\section{Materials and methods}

\section{UNICEF conceptual framework and model specification}

The analysis is performed under UNICEF conceptual framework that constitutes three levels of causes of under-nutrition; immediate, underlying and basic levels (UNICEF, 1990). This framework presents the general relationship between a set of variables and child nutritional level. The immediate level causes comprise of dietary intake and illness which are interlinked. If a child could not take nutritious food he/she may be attacked by infectious diseases due to illness. On the other hand, if a child falls ill then he/she may not be able to consume desired diet which in turn results into malnourishment. Whether a child is in danger of infectious disease or whether he/she gets insufficient food to consume, is the consequence of the underlying factors that are consider as the household causes of under-nutrition. According to the framework of household food security, maternal and child care and environmental factors are the main causes under this level. The causes at the third level of the framework are the basic causes which comprise of political, economic, genetic and socio-cultural factors.

Following the example of Akin et al. (1986) the specified econometric model of this study is based on discrete choice models. Derivation of discrete choice models is based on the hypothesis that the choice of an individual follows the maximization behavior of the random utility (Anye and Yene, 2016). The utility $V_{i j}$ that $i$ th child falling in the jth category of CIAF is given by:

$$
U_{i j}=z_{i}^{b} \alpha+x_{i j}^{b} \beta_{i}+\varepsilon_{i j}
$$

where $V_{i j}$ stands for nutritional outcome of the $i$ th child falling in the $j$ th category of CIAF, $z_{i}$ varies over upper nest alternatives and $\boldsymbol{x}_{i j}$ varies over both upper and lower nest alternatives.

\section{Data source and construction of variables}

Pakistan Demographic and Health Survey (PDHS) data, version 2012-13, is used for the analysis. Two stage sampling technique was used for the survey. At first stage 500 primary sampling units (248 urban and 252 rural) were selected by using probability proportional to size. At second stage systematic sampling technique was used to select 
fixed no of household (28) from primary sampling units selected at first stage. A sample of 14,000 household was selected. Out of 14,569 eligible women, 13,558 were successfully interviewed from these selected households. These women contributed a total of 11,763 live born children within five years before the survey. However, the analysis in this study was limited to 1870 live born children of age 0-59 months ( $<5$ years) who have valid information about the anthropometric measures. Complete details about sampling procedure and data collection can be found elsewhere (Final Report PDHS 2012-2013).

\section{Response variable}

The response variable in this study is the new policy-relevant anthropometric indicator of under-nutrition known as CIAF. The proposed CIAF comprises seven anthropometric failure groups. A Child with height-for-age Z-score (HAZ), weight-forheight Z-score (WHZ) and weight-for-age Z-score (WAZ), below -2 standard deviations from the median of the WHO reference population, are considered to be stunted, wasted and underweight respectively (PDHS report, 2012-13). All these children were distributed into seven groups following Nandy et al., 2005. The details of groups are given in Table 1.

Table 1. Different groups used for construction of response variable (CIAF)

\begin{tabular}{c|c|c|c|c|c}
\hline Group & Description & Wasting & Stunting & Underweight & $\mathbf{N}(\%)$ \\
\hline A & No failure & No & No & No & $933(49.9)$ \\
B & Wasting only & Yes & No & No & $70(3.7)$ \\
C & Wasting \& Underweight & Yes & No & Yes & $67(3.6)$ \\
D & Wasting, Stunting \& Underweight & Yes & Yes & Yes & $93(5.0)$ \\
E & Stunting \& Underweight & No & Yes & Yes & $305(16.3)$ \\
F & Stunting only & No & Yes & No & $374(20.0)$ \\
Y & Underweight only & No & No & Yes & $28(1.5)$ \\
\hline
\end{tabular}

Wasted children $=70+67+93=230(12.3 \%) ;$ Stunted children $=93+305+374=772(41.3 \%)$

Underweight $=67+93+305+28=493(26.4 \%) ;$ No of children fall in CIAF $=937(50.1 \%)$

\section{Explanatory variables}

A range of indicators were included in the analysis under different layers of UNICEF's conceptual framework. The data were extracted from the PDHS data and recategorized (where necessary). These indicators include vaccination status (categorized as non-vaccinated, who did not receive a single dose of any of the prescribed vaccines, partially-vaccinated, who has receive at least one of the vaccine but not complete doses and fully-vaccinated, who received the complete dose of all vaccines), household wealth status was used as proxy for wealth index, given in the survey data, generated by applying principal component analysis on the factors of household ownership of assets (such as bicycle, motorcycle, car, radio, television, etc.) and characteristics of dwellings (such as roof material, main floor material, etc). The index was subsequently cut into quintiles as poorest, poorer, middle, richer and richest and we have re-categorize by merging poorest and poor to only poor and similarly by merging rich and riches and consider as rich only. In this way we have three categories for wealth status as poor, middle and rich. Type of toilet facility was categorized as poor quality, intermediate 
quality and high quality following the method of (Fink et al., 2011). Maternal nutritional level was measured using the BMI (calculated as mother's weight in kilograms ( $\mathrm{kg}$ ) divided by her height in meters squared) and categorized as overweight (if $\mathrm{BMI} \geq 25.0)$, normal $(18.5 \leq \mathrm{BMI} \leq 25.0)$ and underweight (if $\mathrm{BMI} \leq 18.5$ ). Mother's autonomy was based on four questions asked to the respondent regarding who take the decisions in the household about her own health care, large purchase, visit to family/relatives and the consumption of husband earnings. The possible answers were as follows: (i) Respondent alone, (ii) Respondent and husband/partner, (iii) Husband/partner alone, (iv) family elders and (v) others. A value of 1 was assigned if the answer was (i) or (ii) and 0 for (iii), (iv) or (v), for each question. These recoded values were then added to get a score ranging from 0 to 4 . These scores were then categorized into three categories as: no-autonomy if the score value is 0 , partial autonomy if the score value is 1,2 or 3 and the full autonomy if she got a score 4 . Different regions are presented in Figure Al and different categories of considered factors can be seen in Table Al in the Appendix.

\section{Methodology of analysis}

Analysis is conducted in three stages i.e. descriptive analysis, classification tree analysis and regression analysis based on multinomial nested logit modeling. Percentage distribution of explanatory variables and CIAF categories were explained at first stage. In order to find most effecting maternal factors and their inherent associations with CIAF, we consider a non-parametric techniques, known as classification tree (CT) formalized by (Breiman et al., 1984). It works as an exploratory procedure and select the exposure variables that are most important for analyzing the behaviour of response variable. The CT has tree like structure, where terminal nodes represent the CIAF categories. The initial node split the data into two subsets which are further split to second level partition. By default, Gini index is the splitting criteria used in CT (Pawloski and Kitsantas, 2008). An indicator split is known as best split if it observes relatively high value of homogeneity, measured through Gini impurity function, in the node. The impurity got maximized if all observations are equally distributed among different categories of the variable, which implies that at these nodes provides least interesting information. Gini index got minimized if all the observations belong to only one category of the variable which implies that this node provides most interesting information. The tree stops growing if the terminal nodes approach either of these two conditions (Jung et al., 2014).

For regression analysis Equation 1 can be summarized by:

$$
V_{i j}=V_{i j}+\varepsilon_{i j}
$$

Here the term $V_{i j}$ is the observable component of child under-nutrition (comprising of immediate, underlying and basic factors) and $\varepsilon_{i j}$ is the unobservable random part. The probability of a child falling in category $\mathrm{j}$ is equal to the probability of such a category that yield a maximum level of utility for him, that is

$$
\begin{gathered}
P_{i j}=\operatorname{Pr}\left(U_{i j}>U_{i k}\right) ; \forall j \neq k \\
P_{i j}=\operatorname{Pr}\left(V_{i j}+\varepsilon_{i j}>V_{i k}+\varepsilon_{i k}\right) ; \forall j \neq k
\end{gathered}
$$




$$
P_{i j}=\operatorname{Pr}\left(V_{i j}-V_{i k}>\varepsilon_{i k}-\varepsilon_{i j}\right) ; \forall j \neq k
$$

Since the econometric specification depends upon the hypothesis regarding the distributional form of the error term of Equation 5. If the error term is assumed to follow normal distribution, then the estimated model would be a probit model. Though a probit model relax the IIA property and is attractive; however, probit models are infeasible due to their computational difficulties (Ben-Akiva et al., 1985; Adhikari, 2011). An alternative way to model this type of phenomenon is that $\varepsilon_{i j}$ is assumed to follow generalized extreme value (GEV) distribution. By assuming the GEV distribution, a closed form model can be estimated using maximum likelihood method. According to (McFadden, 1981) it produces multinomial logit model $P_{i j}=\exp \left(V_{i j}\right) / \Sigma_{j} \exp \left(V_{i j}\right)$. However, this specification may create a severe problem. Since multinomial logit model assumes that unobservable terms ( $\varepsilon_{i j}$ 's) are identically and independently distributed (IID) and the assumption of independence of irrelevant alternatives (IIA) is not violated. In our case, some of the categories of CIAF are likely to share the error terms and thus be correlated that may violate the IIA property. To circumvent this situation, a more generalized form of multinomial logit model is referred to as multinomial nested logit (MNL) model (McFadden, 1981) which relax IIA assumption (Anya and Yene, 2016). The use of MNL procedure implies that the under-nutrition categories can be organized into an understandable nesting structure. Consider that the nesting structure of the $\mathrm{j}$ alternatives can be seen in Figure 1.

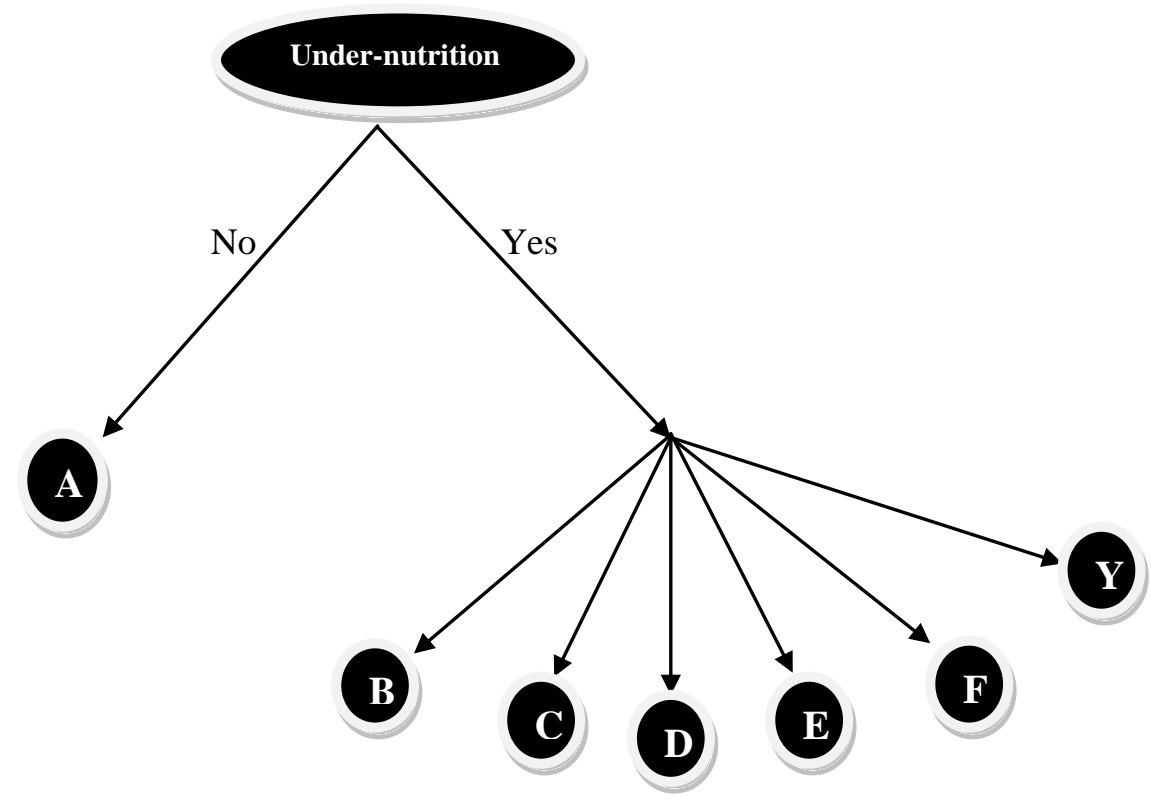

Figure 1. Two-level nested structure of groups of CIAF

A child may fall into one of the two categories (i. e. nourished or not-nourished) and if he/she fall in not-nourished category then he/she fall in one of the six categories of CIAF (i.e. B, C, D, E, F, Y). The probability that a child fall in category $i$ given that he/she is malnourished is given by the equation:

$$
P_{\mathrm{ij}}=P_{\mathrm{i}} * P_{j / \mathrm{i}}
$$


where $P_{j / \mathrm{i}}$ is the conditional probability of falling in the $j$ th category being in $i$ th category of under-nutrition (i.e. at lower-nest) and $P_{i \mathrm{i}}$ is the marginal probability of falling in $i$ th alternative at upper-nest. Moreover,

$$
\begin{gathered}
P_{i}=\frac{\exp \left[z_{i} \alpha+\tau_{i} I_{i}\right]}{\sum_{i=1}^{U} \exp \left[z_{i}^{f} \alpha+\tau_{i} I_{i}\right]} \\
P_{j / i}=\frac{\exp \left[x_{i j} \beta_{j / j}\right]}{\sum_{j=1}^{J} \exp \left[x_{i j} \beta_{j / i}\right]}
\end{gathered}
$$

with $I_{i}=\ln \left(\Sigma_{j=1}^{J} \exp \left[x_{i j} \beta_{j j i}\right]\right)$. Here $I_{i}$ is the inclusive value representing the maximum value of the attributes that determine the probability of a child falling in categoryi. $\tau_{i}$ is the coefficient and its value must ranges from zero to one to be consistent with the NL derivation (McFadden, 1981). The NL model is estimated using full information maximum likelihood procedure. This method estimates the parameters in all stages simultaneously and produces consistent and efficient results (Hu and Donnell, 2010). Stata version 14 and Party-package of $\mathrm{R}$ were used for the regression analysis and classification trees respectively.

\section{Results}

\section{Descriptive analysis}

A total of 1870 , children of age $<5$ yrs were included in the analysis. Out of these children, about half (934 out of 1870) were female. According to the conventional indices of under-nutrition, $41.3 \%$ (772 out of 1870) were stunted, $12.3 \%$ (230 out of 1870) were wasted and $26.4 \%$ (493 out of 1870) were underweight among the studied sample. However, according to the CIAF, about 51\% (937 out of 1870) of the children suffer from at least one of the groups (Group B-Y) and overall 49.9\%(933 out of 1870) of the children fall in Group-A (i.e. without any failure). The highest prevalence of malnourishment was found to be in Group-F (20\%: 374 out of 1870) followed by Group-E (16.3\%: 305 out of 1870) while, Group-Y it was observed to be lowest with respect to malnourishment (1.5\%: 28 out of 1870). Moreover, it was found to be approximately same in Group-B (3.7\%: 70 out of 1870) and Group-C (3.6\%: 67 out of 1870).

Majority of the mothers were uneducated $(51.44 \%$; 962 out of 1870) and have no autonomy (45.7\%: 855 out of 1870) while, least of the women were underweight (12\%: 225 out of 1870) among the studied sample. Prevalence of malnourished children among the poor and non-educated mothers remained high in failure groups $\mathrm{E}$ and $\mathrm{F}$ ( $23.3 \% \& 25 \%$ for poor and $21.3 \% \& 237 \%$ for non-educated mothers respectively). Moreover, percentage of undernourished children was lower in case of working mother (34.6\%; 120 out of 347). Underweight mothers have high ratio of underweight and stunted children (i.e. Group-E: 29.3\%; 66 out of 225). Six hundred and thirty six (34\%: 636 out of 1870) children were resident of Punjab region followed by region Sindh (24\%: 450 out of 1870). Percentage of nourished children stood high for Islamabad region (70.6\%). About $40 \%$ (755 out of 1870) of the children belong to poor families (Table 2). 
Table 2. Percentage distribution of socio-economic and demographic factors of CIAF

\begin{tabular}{|c|c|c|c|c|c|c|c|c|c|}
\hline \multirow{3}{*}{ Variables } & \multirow{2}{*}{\multicolumn{2}{|c|}{ Total }} & \multicolumn{7}{|c|}{ Different categories of CIAF } \\
\hline & & & \multirow{2}{*}{$\begin{array}{l}\text { A } \\
\% \\
\end{array}$} & \multirow{2}{*}{$\begin{array}{l}\text { B } \\
\% \\
\end{array}$} & \multirow{2}{*}{$\begin{array}{l}\mathrm{C} \\
\% \\
\end{array}$} & \multirow{2}{*}{$\begin{array}{l}\text { D } \\
\% \\
\end{array}$} & \multirow{2}{*}{$\begin{array}{l}\mathrm{E} \\
\%\end{array}$} & \multirow{2}{*}{$\begin{array}{l}\mathbf{F} \\
\%\end{array}$} & \multirow{2}{*}{$\begin{array}{l}\mathrm{Y} \\
\%\end{array}$} \\
\hline & $\mathbf{f}$ & $\%$ & & & & & & & \\
\hline \multicolumn{10}{|c|}{ Regions } \\
\hline Punjab & 636 & 34.0 & 55.8 & 2.8 & 3.5 & 3.9 & 15.4 & 17.0 & 1.5 \\
\hline Sindh & 450 & 24.1 & 37.6 & 3.3 & 4.7 & 7.8 & 26.0 & 18.0 & 2.7 \\
\hline KPK & 316 & 16.8 & 57.6 & 3.8 & 4.1 & 4.1 & 13.9 & 15.8 & 0.6 \\
\hline Blochistan & 176 & 9.4 & 25.0 & 2.3 & 2.3 & 9.1 & 17.6 & 43.2 & 0.6 \\
\hline GB & 172 & 9.3 & 57.2 & 6.4 & 2.3 & 1.2 & 5.8 & 27.2 & 0.0 \\
\hline Islamabad & 119 & 6.4 & 70.6 & 8.4 & 2.5 & 1.7 & 4.2 & 10.1 & 2.5 \\
\hline \multicolumn{10}{|c|}{ Type of residence } \\
\hline Urban & 789 & 42.2 & 56.3 & 4.3 & 2.7 & 4.6 & 12.3 & 18.4 & 1.4 \\
\hline Rural & 1081 & 57.8 & 45.2 & 3.3 & 4.3 & 5.2 & 19.2 & 21.2 & 1.6 \\
\hline \multicolumn{10}{|c|}{ Gender } \\
\hline Male & 936 & 50.1 & 48.1 & 3.8 & 3.9 & 5.8 & 17.0 & 19.9 & 1.5 \\
\hline Female & 934 & 49.9 & 51.7 & 3.6 & 3.2 & 4.2 & 15.6 & 20.1 & 1.5 \\
\hline \multicolumn{10}{|c|}{ Wealth status } \\
\hline Poor & 755 & 40.4 & 35.6 & 2.9 & 4.1 & 7.7 & 23.3 & 25.0 & 1.3 \\
\hline Middle & 363 & 19.4 & 50.1 & 5.2 & 4.4 & 2.5 & 14.3 & 21.2 & 2.3 \\
\hline Rich & 752 & 40.2 & 64.1 & 3.9 & 2.7 & 3.4 & 10.2 & 14.4 & 1.3 \\
\hline \multicolumn{10}{|c|}{ Mother's education } \\
\hline No education & 962 & 51.4 & 38.6 & 3.3 & 4.5 & 7.2 & 21.3 & 23.7 & 1.5 \\
\hline Primary & 311 & 16.6 & 48.9 & 5.1 & 2.6 & 2.9 & 18.3 & 19.3 & 2.9 \\
\hline Secondary & 387 & 20.7 & 68.0 & 3.4 & 2.8 & 3.1 & 8.3 & 13.7 & 0.8 \\
\hline Higher and above & 210 & 11.2 & 70.0 & 4.3 & 2.4 & 1.4 & 5.2 & 15.7 & 0.9 \\
\hline \multicolumn{10}{|c|}{ Vaccination } \\
\hline Not vaccinated & 178 & 9.5 & 35.4 & 5.1 & 3.9 & 7.3 & 20.2 & 27.5 & 0.6 \\
\hline Partially vaccinated & 1094 & 58.5 & 48.8 & 4.1 & 3.5 & 4.8 & 17.5 & 19.5 & 1.8 \\
\hline Fully vaccinated & 598 & 32.0 & 56.2 & 2.7 & 3.7 & 4.5 & 13.0 & 18.7 & 1.2 \\
\hline \multicolumn{10}{|c|}{ Working mother } \\
\hline No & 1523 & 81.4 & 53.4 & 3.8 & 3.6 & 4.5 & 14.4 & 19.0 & 1.3 \\
\hline Yes & 347 & 18.6 & 34.6 & 3.5 & 3.5 & 7.2 & 24.5 & 24.5 & 2.3 \\
\hline \multicolumn{10}{|c|}{ Had diarrhea } \\
\hline No & 1430 & 76.5 & 51.0 & 3.6 & 2.8 & 4.3 & 16.5 & 20.4 & 1.4 \\
\hline Yes & 440 & 23.5 & 46.4 & 4.1 & 6.1 & 7.0 & 15.7 & 18.9 & 1.8 \\
\hline \multicolumn{10}{|c|}{ Mother's BMI } \\
\hline Normal & 1098 & 58.7 & 47.8 & 4.1 & 3.3 & 4.9 & 17.7 & 20.5 & 1.7 \\
\hline Underweight & 225 & 12.0 & 36.0 & 2.2 & 5.8 & 10.7 & 29.3 & 15.1 & 0.9 \\
\hline Overweight & 547 & 29.3 & 59.8 & 3.7 & 3.3 & 2.7 & 8.2 & 21.0 & 1.3 \\
\hline & & & Mother' & utonom & & & & & \\
\hline No autonomy & 855 & 45.7 & 47.6 & 3.4 & 3.9 & 5.3 & 17.1 & 21.2 & 1.6 \\
\hline Partial-autonomy & 532 & 28.5 & 57.5 & 2.6 & 2.6 & 5.3 & 14.5 & 16.2 & 1.3 \\
\hline Full-autonomy & 483 & 25.8 & 45.6 & 5.6 & 4.1 & 4.1 & 17.0 & 22.2 & 1.4 \\
\hline & & & Toil & type & & & & & \\
\hline High quality & 1270 & 68.0 & 38.3 & 3.4 & 4.8 & 7.8 & 23.0 & 21.3 & 1.4 \\
\hline Medium quality & 187 & 10.0 & 36.9 & 2.7 & 2.1 & 7.0 & 19.2 & 30.5 & 1.6 \\
\hline Poor quality & 413 & 22.1 & 55.6 & 4.0 & 3.4 & 3.8 & 13.7 & 18.0 & 1.5 \\
\hline & & & $x$ of hor & hold he & & & & & \\
\hline Male & 1740 & 93.1 & 50.3 & 3.7 & 3.7 & 5.1 & 15.7 & 20.0 & 1.6 \\
\hline Female & 130 & 6.9 & 44.6 & 4.6 & 2.3 & 3.9 & 24.6 & 20.0 & 0.0 \\
\hline Total & 1870 & 100.0 & 49.9 & 3.7 & 3.6 & 5.0 & 16.3 & 20.0 & 1.5 \\
\hline
\end{tabular}




\section{Classification tree analysis}

Two classification trees were constructed in our study. Figure A2 (Appendix) demonstrates the first tree where mother's related variables (mother's education, mother's autonomy, mother's BMI, household wealth status and working status of mother) were considered. At the primary split the nutritional status of child is divided into two groups according to the mother's education (one is secondary and higher and the other is non-educated and primary). Subsequently node 2 is further divided according to the mother's BMI (underweight; normal and overweight) while, node 5 split into two groups according to wealth status (poor, middle and rich) while, node 6 and 9 are also split according to the mother's BMI (underweight; normal and overweight). There are total 11 nodes. There is higher percentage (about 20\%; terminal node 3) of malnourished child with stunting and underweight (Group-F) whose mother has higher or secondary education with low BMI (underweight) while, about $70 \%$ of children are well nourished (Group-A) if the mother's nutritional level is better (i.e. she is normal or overweigh). Moreover, about $40 \%$ children (terminal node 8 ) belongs to mothers who either have primary education or non-educated, with lower BMI, are stunted and underweight (Group-E). Middle class or rich mothers with lower nutritional status have about $25 \%$ of the children with failure groups $\mathrm{E}$ and $\mathrm{F}$ (terminal node, 10). In the second tree (Fig. A3 in the Appendix), impact of interactions of mother's schooling and working status on her child's nutritional level was presented. At the top, mother's education is divided into two groups (one is secondary and higher and the other is non-educated and primary). If the mother has secondary or higher education, about $70 \%$ of the children are with Group-A (i.e. well nourished; terminal node, 2) while, we move to node 3 if the mother has either primary- or no-education which further split mother's working status in two groups (yes and no). Node 4 showed that about $25 \%$ of the children prone to failure Groups $\mathrm{E}$ and $\mathrm{F}$ who belongs to working mothers with primary or no-education. However, if their mother is not working, the nutritional status of children of mothers having primary education is better than that of non-educated mothers (about 55\% vs. 40\%: terminal node 6 and 7).

\section{Multinomial nested logit analysis}

Associations of different groups of CIAF (Group B-Y) and various demographic and socio-economic factors, based on nested logit model, are shown in Table 3 (Odd ratios and estimates with standard errors for upper nest) and Table 4 (Odd ratios and estimates with standard errors for lower nest). The results at lower nest suggested that children, observed to have group C, D and E, were found a higher significant association with various exposure variables at that level. Table 3 shows that inclusive value at lower nest was found to be 0.38 with $\mathrm{p}$-value $<0.05$, which suggests that shared unobservable are significantly present between different categories of CAIF (Group B-Y). According to the Wald-test the nesting structure is appropriate (Wald chi2 $=230.13$, p-value $<0.001$ ) while, likelihood ratio test for IIA property indicates that nested logit, is in fact, probably more convenient (chi2 $(1)=15.43$, p-value $<0.001)$. The results and interpretations of variables at lower nest are briefly given below.

Effect of mother education: Mother education was found to be a highly significant factor of CIAF groups (Groups B-Y). Children of mothers with secondary education as compared to non-educated mothers were at about 50\% lower risk to be lying in groups $\mathrm{C}, \mathrm{D}, \mathrm{E}$ and F (Table 4). However, this percentage fall down to $40 \%(\mathrm{OR}=0.61)$ for 
group-B. If mother's education improved (higher and above), the nutritional level of children also improved. The results stated significantly lower odds for those children whose mothers have higher or above education. $\mathrm{OR}=0.34$, for group-D and $\mathrm{OR}=0.40$, for group-E). Moreover, mother's primary education does not show a significant association, implying that there exist no relative difference among the children of non educated mothers and those with primary education, regarding under-nutrition.

Effect of vaccination: The association of CIAF groups showed that vaccinated children were less likely to be malnourished as compared to non-vaccinated children. The odd values were significantly lower for the children of failure Group-B $(\mathrm{OR}=0.55)$, Group-C $(\mathrm{OR}=0.53)$, Group-D $(\mathrm{OR}=0.57)$ and Group-Y $(\mathrm{OR}=0.51)$. Those who were completely vaccinated have about $50 \%$ lower risk to fall in failure group-B $(\mathrm{OR}=0.52)$ and Group-Y $(\mathrm{OR}=0.50)$. However, the association of fully vaccinated children remained insignificant.

Effect of mother's Working Status: The impact of mother's working status was found to have higher effect on child under-nutrition. There were 36 percent more chances of falling in Group-F $(\mathrm{OR}=1.36)$ and $31 \%$ more chance of lying in Group-F for the children of working mothers $(\mathrm{OR}=1.31)$.

Effect of Diarrhea: Child who had diarrhea within two weeks prior to survey were found to have significantly higher odds for those suffering from wasting and underweight group (Group-C: $\mathrm{OR}=1.48$ ) and multiple failure group (Group-D: $\mathrm{OR}=1.38$ ).

Table 3. Nested logit analysis of factors at upper nest

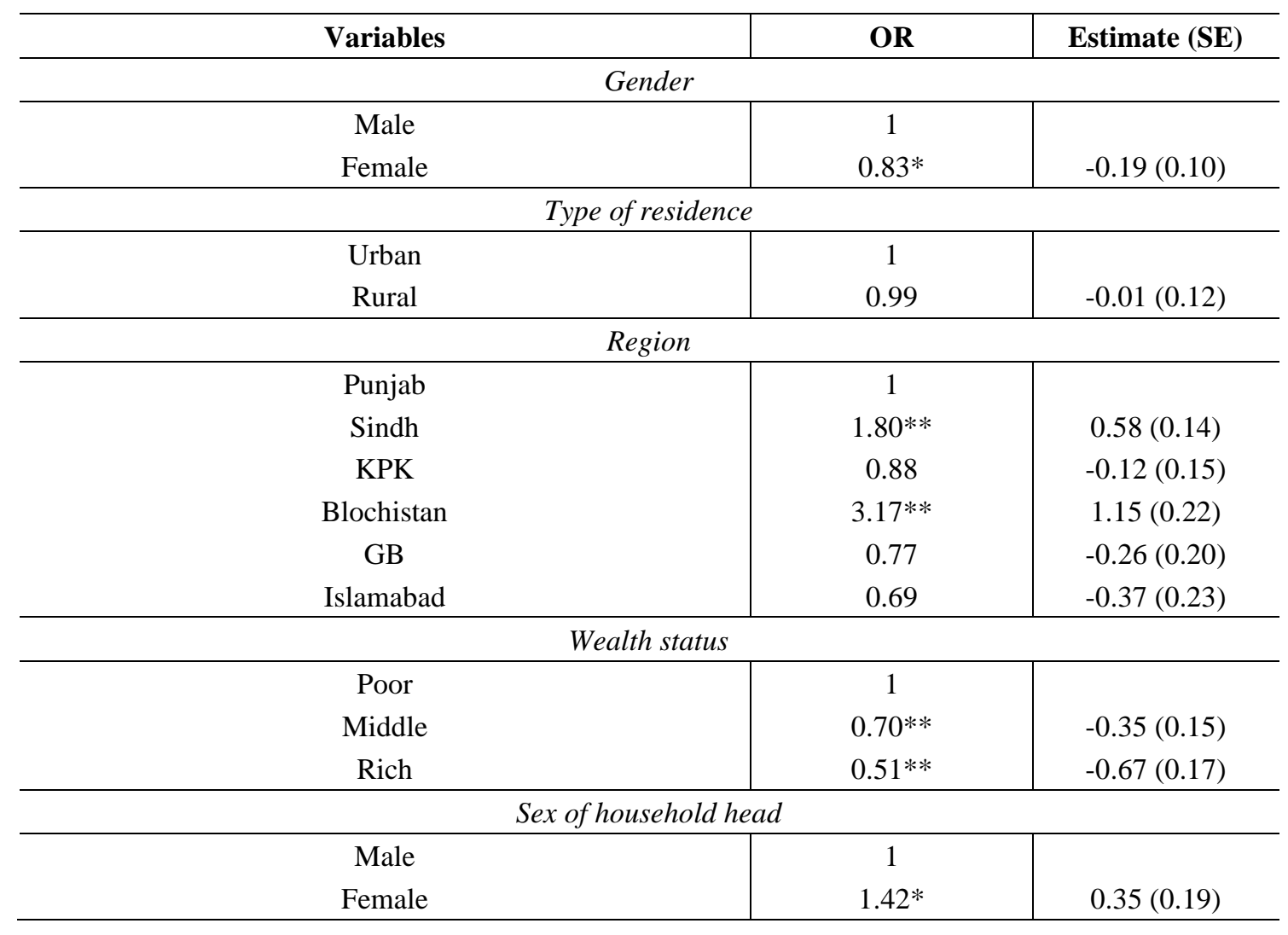

Inclusive value $=0.39 ; \mathrm{P}$-value $<0.05 ;$ Wald chi2 $(88)=230.13 ; \mathrm{P}$-value $<0.001 ;$ Log-likelihood $=$ 2487.13; LR test for IIA: chi2 $(1)=15.43$; P-value < 0.001. $\mathrm{N}=1870$; OR: odd ratios; $* *<.05, *<.10$ 
Table 4. Factors associated with different groups of CIAF at lower nest

\begin{tabular}{|c|c|c|c|c|c|c|c|c|c|c|c|c|}
\hline \multirow[b]{2}{*}{ Variables } & \multicolumn{2}{|c|}{ Group B } & \multicolumn{2}{|c|}{ Group C } & \multicolumn{2}{|c|}{ Group D } & \multicolumn{2}{|c|}{ Group E } & \multicolumn{2}{|c|}{ Group F } & \multicolumn{2}{|c|}{ Group Y } \\
\hline & OR & $\begin{array}{l}\text { Estimate } \\
\text { (SE) }\end{array}$ & OR & $\begin{array}{c}\text { Estimate } \\
\text { (SE) }\end{array}$ & OR & $\begin{array}{c}\text { Estimate } \\
\text { (SE) }\end{array}$ & OR & $\begin{array}{c}\text { Estimate } \\
\text { (SE) }\end{array}$ & OR & $\begin{array}{c}\text { Estimate } \\
\text { (SE) }\end{array}$ & OR & $\begin{array}{l}\text { Estimate } \\
\text { (SE) }\end{array}$ \\
\hline \multicolumn{13}{|c|}{ Mother's education } \\
\hline No education & Ref & & $\begin{array}{l}\text { Ref } \\
074\end{array}$ & & Ref & & Ref & & Ref & & $\begin{array}{l}\text { Ref } \\
109\end{array}$ & \\
\hline Primary & $\begin{array}{c}1.09 \\
0.61 * *\end{array}$ & $\begin{array}{c}0.09(0.19) \\
-050(020)\end{array}$ & $\begin{array}{c}0.74 \\
0.49 * *\end{array}$ & \begin{tabular}{|ll}
-0.29 & $(0.23)$ \\
-0.71 & $(020)$
\end{tabular} & $\begin{array}{c}0.69 \\
0.46 * *\end{array}$ & $\begin{array}{l}-0.36(0.24) \\
-0.78(0.20)\end{array}$ & $\begin{array}{c}0.99 \\
0.49 * *\end{array}$ & $\begin{array}{l}-0.01(0.16) \\
-0.72(0.17)\end{array}$ & $\begin{array}{c}0.94 \\
0.55^{* *}\end{array}$ & $\begin{array}{l}-0.06(0.15) \\
-0.60(0.16)\end{array}$ & $\begin{array}{c}1.09 \\
0.43^{* *}\end{array}$ & $\begin{array}{c}0.09(0.22) \\
-0.85(0.29)\end{array}$ \\
\hline $\begin{array}{c}\text { Secondary } \\
\text { Higher and above }\end{array}$ & $\begin{array}{c}0.61 * * \\
0.67\end{array}$ & $\begin{array}{l}-0.50(0.20) \\
-0.40(0.28)\end{array}$ & $\begin{array}{l}0.49^{* *} \\
0.46^{* *}\end{array}$ & \begin{tabular}{|l}
$-0.71(0.20)$ \\
$-0.78(0.27)$
\end{tabular} & $\begin{array}{l}0.46^{* *} \\
0.34 * *\end{array}$ & $\begin{array}{l}-0.78(0.20) \\
-1.09(0.33)\end{array}$ & $\begin{array}{l}0.49^{* *} \\
0.41^{* *}\end{array}$ & $\begin{array}{l}-0.72(0.17) \\
-0.90(0.24)\end{array}$ & $\begin{array}{l}0.55^{* *} \\
0.54 * *\end{array}$ & $\begin{array}{l}-0.60(0.16) \\
-0.62(0.21) \\
\end{array}$ & $\begin{array}{l}0.43^{* *} \\
0.45^{* * *} \\
\end{array}$ & $\begin{array}{l}-0.85(0.29) \\
-0.80(0.35) \\
\end{array}$ \\
\hline \multicolumn{13}{|c|}{ Vaccination } \\
\hline Not vaccinated & Ref & & Ref & & Ref & & Ref & & Ref & & Ref & \\
\hline Partially vaccinated & $0.56 * *$ & $-0.59(0.27)$ & $0.53 * *$ & $-0.62(0.28)$ & $0.57 * *$ & $-0.57(0.26)$ & 0.86 & $-0.15(0.16)$ & 0.86 & $-0.14(0.15)$ & $0.51^{* *}$ & $-0.68(0.32)$ \\
\hline Fully vaccinated & 0.52 & $-0.66(0.36)$ & 0.67 & $-0.40(0.27)$ & 0.73 & $-0.32(0.25)$ & 0.98 & $-0.01(0.18)$ & 1.04 & $0.04(0.17)$ & 0.5 & $-0.69(0.40)$ \\
\hline \multicolumn{13}{|c|}{ Working mother } \\
\hline No & Ref & & Ref & & Ref & & Ref & & Ref & & Ref & \\
\hline Yes & 1.14 & $0.13(0.20)$ & 1.07 & $0.07(0.21)$ & 1.28 & $0.25(0.17)$ & $1.36 * *$ & $0.31(0.15)$ & $1.31 * *$ & $0.27(0.15)$ & 1.42 & $0.35(0.22)$ \\
\hline \multicolumn{13}{|c|}{ Had diarrhea } \\
\hline No & Ref & & Ref & & Ref & & Ref & & Ref & & Ref & \\
\hline Yes & 1.17 & $0.16(0.16)$ & $1.48 * *$ & $0.39(0.16)$ & $1.38 * *$ & $0.32(0.15)$ & 1.15 & $0.15(0.13)$ & 1.16 & $0.15(0.12)$ & 1.15 & $0.14(0.19)$ \\
\hline \multicolumn{13}{|c|}{ Mother's BMI } \\
\hline Normal & Ref & & Ref & & Ref & & Ref & & Ref & & Ref & \\
\hline Underweight & 1.06 & $0.06(0.28)$ & $1.57 * *$ & $0.46(0.20)$ & $1.73 * *$ & $0.55(0.19)$ & $1.64 * *$ & $0.49(0.17)$ & 1.24 & $0.21(0.19)$ & 0.92 & $-0.08(0.38)$ \\
\hline Overweight & 0.82 & $-0.20(0.16)$ & 0.87 & $-0.14(0.15)$ & $0.74 *$ & $-0.39(0.17)$ & $0.74 *$ & $0.30(0.15)$ & 0.99 & $-0.01(0.13)$ & 0.72 & $-0.33(0.21)$ \\
\hline \multicolumn{13}{|c|}{ Mother's autonomy } \\
\hline No autonomy & Ref & & Ref & & Ref & & Ref & & Ref & & Ref & \\
\hline Single autonomy & 0.89 & $-0.11(0.18)$ & 0.87 & $-0.14(0.18)$ & 1.06 & $0.06(0.15)$ & 1.02 & $0.02(0.14)$ & 0.96 & $-0.04(0.13)$ & 0.85 & $-0.16(0.22)$ \\
\hline Multiple autonomy & $1.31 *$ & $0.27(0.16)$ & 1.09 & $0.09(0.16)$ & 0.02 & $0.02(0.18)$ & 1.16 & $0.16(0.14)$ & 1.22 & $0.20(0.13)$ & 0.91 & $-0.08(0.24)$ \\
\hline \multicolumn{13}{|c|}{ Toilet type } \\
\hline High quality & Ref & & Ref & & Ref & & Ref & & Ref & & Ref & \\
\hline Medium quality & 0.63 & $-0.45(0.30)$ & 0.58 & $-0.52(0.33)$ & 0.85 & $-0.16(0.22)$ & 0.9 & $-0.10(0.20)$ & 1.04 & $0.04(0.20)$ & 0.59 & $-0.53(0.35)$ \\
\hline Poor quality & 0.79 & $-0.23(0.21)$ & 0.85 & $-0.15(0.18)$ & 0.92 & $-0.08(0.17)$ & 1.01 & $0.01(0.14)$ & 0.99 & $-0.01(0.14)$ & 0.64 & $-0.45(0.30)$ \\
\hline
\end{tabular}

$\mathrm{N}=1870$; OR: odd ratios; $* *<.05, *<.10 ; \mathrm{SE}$ : standard error 
Effect of Mother's BMI: Children of under-weight mother's were found to have significantly higher odds of falling in Group-C ( $\mathrm{OR}=1.57)$, Group-D (OR = 1.73) and Group-E $(\mathrm{OR}=1.64)$. While, the children of overweight mother were less likely to be malnourished ( $\mathrm{OR}=0.74$ for Group-D and $\mathrm{OR}=0.74$ for Group-E).

Mother's autonomy as well as toilet facility is among the important factors of UNICEF framework but their association could not found to be significant. We turn to the results and interpretation of variables at upper nest. A brief description is given below:

Effect of Gender: There were 17\% lower chance of falling in under-nutrition for female child $(\mathrm{OR}=0.87$ ) as compared to the male child.

Effect of Wealth Status: Wealth status is among the important factors affecting child's nutritional status at upper nest. The children of middle class families were $30 \%$ $(\mathrm{OR}=0.70)$ less likely to be malnourished while, rich children were at $49 \%$ at lower risk of under-nutrition as compared to poor children $(\mathrm{OR}=0.51)$.

Regional Effects: Geographic location affects the health status of child. There were $80 \%(\mathrm{OR}=1.79)$ more chances of falling in under-nutrition for Sindhi child. However, the children of Baluchistan were three times more likely to fall in the anthropometric failure $(\mathrm{OR}=3.17)$ as compared to the children of Punjab. There is no significant difference between KPK, GB and Islamabad regions as compared to Punjab with respect to child under-nutrition.

Type of Place of Residence: there exist no significant association between type of place of residence and child under-nutrition.

Sex of Household Head: children of female headed household were $42 \%$ more likely to be malnourished as compared to children of male headed households $(\mathrm{OR}=1.42)$.

\section{Discussion}

Assessment of the nutritional status of children (of age $<5$ yrs) plays an important role in developing countries, such as Pakistan, where the major part of population is malnourished (Sen and Mondal, 2012). According to the conventional measures, the prevalence of stunting, wasting and underweight remained $41.3 \%, 12.3 \%$ and $26.4 \%$ respectively among the studied sample, while the prevalence of under-nutrition was $51.1 \%$ using the CIAF. Based on the CIAF, the results of this study are higher as compared to other countries such as Ethiopia (Fentahun et al., 2016), while the position is little bit better than India (Dasgupta et al., 2015).

Classification trees may work as a useful alternative to the traditional statistical techniques such as logistic regression (Pawloski and Kitsantas, 2008). It is one of the data mining techniques that can identify subgroups in the data that share similar characteristics (Marshall, 2001) and display the results graphically which helps in understanding their interpretations. This display of classification tree can help in understanding how maternal factors interact to define and understand the importance of each variable examined. Moreover, some studies provide the comparison of classification trees with logistic regression models (Pawloski and Kitsantas, 2008; Kitsantas et al., 2007) and found that both methodologies provide comparable predictive performance. In this study, the classification trees revealed that mother's schooling is the most important factor among the maternal factor. The data also show that the children of educated (even primary) and healthy mothers living in household with middle or rich wealth status, were more likely to bear better nutritional status while, if 
the mother's education is secondary or above the wealth status does not matter. Furthermore if mother has secondary or higher education then her work status does not affect her child's nutritional health. However, if she has either primary education or noeducation then work status influence her child's nutritional level. Interestingly, mother's autonomy did not appear in the classification tree display (Fig. B1), suggesting that maternal autonomy may not play an important role for the prediction of poor nutritional status in our case. The results suggested by the tree structure also support the findings of nested logit model as well.

There exist a significant association between regions of residence and the nutritional status of children. Children of Balochistan region are at high risk of falling undernutrition followed by region Sindh. Similar results were found in some other studies for Pakistan (Tariq et al., 2018). This may be due the cultural norms, seasonal food insecurity, poor health, and sanitation conditions. There are various aspects of gender discrimination in the literature. Some studies revealed that girls are at greater risk as compared to boys (Khan and Raza, 2014; Petrou and Kupek, 2010), while others demonstrated that male child is more likely to be undernourished (Alemayehu et al., 2015; Kandala et al., 2011). However, some studies showed no discrimination (Arif et al., 2011; Mushtaq et al., 2011). Our results showed that female children are less likely to be malnourished, which are in the line with different examinations on the planet (Poda et al., 2017; Altare et al., 2016; Hazarika, 2000). It may be due to the reason as female are less active and stay at home near food preparation. Another explanation may be that the economies like Pakistan, where women's role is important especially as agriculture labour; women's health is preferred (Akombi et al., 2017). A number of studies addressed that children of urban areas have better nutritional status than rural areas (Ejaz and Azid, 2011; Kandala et al., 2011; Hazarika, 2000). The results of this study uncovered no critical relationship amongst categories of CIAF and sort of place of home. Other studies have also showed the similar result (Poda et al., 2017; Rahman et al., 2015). The findings of this study also demonstrate that children of female headed households were more likely to prone in under nutrition. Commonly female headed households, in middle and low income countries, are those where child's mother is a widow or divorced. These households are generally poorer, own less and have lower access to good jobs which ultimately impact the health status of their residents. Similar results can be found elsewhere (Haidar and Kogi-Makau, 2009).

We examined how mothers 'decision making autonomy was associated with the likelihood of childhood under-nutrition. The finding suggests that mothers' sole decision-making as well as partial decision making was not associated with the likelihood of childhood under-nutrition. This result may suggest that child's nutritional status is not affected by who makes decisions in the household. There exist mixed results regarding mother's autonomy in empirical studies conducted in other countries. For example Deasi and Jhnson (2005) conducted a cross-country study for 12 developing countries, using DHS datasets, found that impact of mother's autonomy on height-for-age was positive for Mali and India however, negative association was found between child's nutrition and height for age in Haiti and Malawi. Non-significant results were also found in some studies (Kamiya et al., 2018).

Maternal education is one of the important factors of child health (Asif et al., 2017). There is an extensive literature supported the consequence that improved maternal education to be one of the protective measures of child's poor nutritional status (Alemayehu et al., 2015; Khan and Raza, 2014; Asena and Teni, 2015; Solanki et al., 
2014; Frongillo et al., 1997). Our study also showed that children of educated mothers (at least secondary) are less likely to fall in CIAF (in Categories B-Y). These results are consistent with other studies (Endris et al., 2017; Poda et al., 2017). An improvement in women's educational status may consider as a proxy for the increment in the household decision making autonomy which further act as a mediator for the relation between child's nutrition and mother's decision making autonomy (Akombi et al., 2017). Another way of explanation may be that an educated mother may get well pay jobs and more empowered in developing countries (Kandala et al., 2011) which positively affect the child's health ultimately. Thus, we may conclude that improved educational status of mother may consider as a protective measure of childhood under-nutrition.

In the present study we have evaluated the association between child's nutrition and mother's anthropometrics characteristic. Results indicated that maternal BMI was significantly associated with children nutritional status. Different Studies round the world showed that underweight mothers were more likely to have malnourished children as compared to normal or overweight mothers (Poda et al., 2017; Debnath and Bhattacharjee, 2016; Rahman et al., 2015; Tigga and Son, 2016; Ajslev et al., 2014; Fleten et al., 2012). This relationship also indicate and intergenerational transfer of socio-economic adversity and poor maternal health to child. Poverty may be another cause of low maternal BMI because poor mother are nutritionally deprived during early age which may not improve even after marriage. Moreover, social causes such early marriage, lack of birth spacing, and discrimination of food distribution in male dominant families may increase under-nutrition among mothers. The results of this study revealed that children of working mothers were more likely to prone undernutrition. This may be due to the reasons: first, is that the working mothers have less time for care and feeding of their offspring. Second, generally the mothers of lowincome families are less educated and engaged in informal work to earn a little money for the survival of their family. Moreover, such families lived in an unclear environment which adversely affects their health. Similar result can be found in the studies conducted for other countries (Toyama et al., 2001). Diarrhea is one of the important factors of child's death and illness in developing countries (Checkley et al., 2008) which may affect the child's health instantly. The findings of this study demonstrated that children with diarrhea were more likely to fall in Group-C and Group-D of CIAF. The reason behind might be that, diarrhea impact the child nutritional status indirectly as a child with diarrhea could not consume food properly and ultimately fall in undernourishment. Childhood vaccination may strengthen children's nutritional level and lead to a better childhood development in low and middle income countries, where $20 \%$ of children fewer than 5 years of age have low weight for age (underweight) and about $32 \%$ have low height for age (stunted). Childhood under-nutrition accounts for $35 \%$ of deaths worldwide among children of fewer than 5 years because it increases the risk of mortality due to infectious diseases (Anekwe and Kumar, 2012). The findings of our study showed that nutritional level can improve even if the child is partially immunized. Though the results for fully vaccinated children has been reported to be insignificant however this finding does not deny the importance of full vaccination for child's better nutritional status (Debnath and Bhattacharjee, 2016).

An association between household wealth status and child nutrition has been shown in several studies (Chowdhury et al., 2016; Poda et al., 2017). It is found that the children of middle class and rich families were less likely to fall in the CIAF. Other studies also demonstrated similar results (Chowdhury et al., 2016; Kandala et al., 2011; 
Petrou and Kupek, 2010; Darteh et al., 2014). This is perhaps due to the reason that well off households may have better access to basic facilities such as good and nutritious food. On the other hand, children of poor SES are more likely to prone anthropometric failure due to insufficient intake, greater exposure to infection as well as lack of access to the basic needs (Hazarika, 2000). A study in Bangladesh has shown that parents of richer families are more likely to be educated than those from poor families, and thus have better access to food, allocate higher proportion of resources for children's welfare and improved standard of living (Sarma et al., 2017), which in turn gives better healthcare to the child. Another study investigating the interaction between SES and the mother's education in connection to child health, found that the impact of improved maternal education turned to be more protective for the children of rich families, while father's education works independently of SES and considered as protective element (Hatt and Waters, 2006).

\section{Conclusion}

A significant association among child under-nutrition and maternal factors in Pakistan underscore the requirement for sustained investment to highlight social factors and reproductive health. Our analysis has identified the most vital determinants influencing the child under-nutrition which may play a crucial role in the literature on the association of CIAF with socio-economic and demographic variables. There is need of interventions by the government in collaboration with non-governmental organizations, like USAID, for the improvement of children's nutritional level, especially in under-developed regions such as Blochistan and Sindh. The local governments representatives (Such as UC chairman, councilors etc.) in cooperation with civil society should work to frame child's nutritional level as a national development agenda. Steps should be taken to improve the maternal status in the society, especially the mother's education and her nutritional level. Such programmes should be launched that focus on increase in the women's role in the society, such as skilled education, well paid job opportunities and better health facilities. Moreover, the interventions for the improvement of household wealth status and the effective nutritional strategies (such as Benazir Income Support Programme (unconditional cash transfer for poverty reduction) and Health/Sehat cards (used for free or reduced-rate medical treatment issued by the government), over the long period, should be considered. However, for short run, maternal and child health programs as well as the provision of supplement food on subsidized rate may be useful for eradication of under-nutrition. The progress in preventive measures for infectious diseases, such as diarrhea, need attention of policymakers to reduce child under-nutrition. Moreover, Lower maternal BMI needs attention in order to break the inter-generational existence of under-nutrition.

The use of CIAF as a measure nutritional status will serve to access more precise identification of nutritionally more vulnerable segments of population since, it has enough potential to improve the efficacy of different nutritional interventions by recognizing different failure groups (single, double and multiple) and also it gives an estimate of overall burden of under-nutrition. Therefore, further research on causes of malnutrition, taking CIAF as measure of malnutrition, is needed. Moreover, reproductive health care, maternal dietary pattern, access to information might be associated with children's nutritional status, therefore further studies should consider such maternal factors also, while investigating the causes of child under-nutrition. 
Moreover, child's dietary pattern should be considered while exploring the causes of child under-nutrition.

Acknowledgments. The authors wish to thank measuredhs.com for giving access to Pakistan demographic and health survey data for 2012-13.

\section{REFERENCES}

[1] Achadi, E., Ahuja, A., Bendech, M. A., Bhutta, Z. A., De-Regil, L. M., Fanzo, J., ... Kimani, E. (2016): Global Nutrition Report 2016: From Promise to Impact: Ending Under-Nutrition by 2030. - International Food Policy Research Institute (IFPRI), Washington, DC.

[2] Achakzai, P., Khan, R. (2016): Nutritional status and associated factors among children less than five years of age in Tehsil Zarghoon town, District Quetta, Baluchistan. Journal of Ayub Medical College Abbottabad 28(1): 146-51.

[3] Adhikari, S. R. (2011): A methodological review of demand analysis: an example of health care services. - Economic Journal of Development Issues 13: 119-30.

[4] Ajslev, T. A., Ängquist, L., Silventoinen, K., Baker, J. L., Sørensen, T. I. (2014): Trends in parent-child correlations of childhood body mass index during the development of the obesity epidemic. - PLoS One 9(10): e109932.

[5] Akin, J. S., Griffin, C. C., Guilkey, D. K., Popkin, B. M. (1986): The demand for primary health care services in the Bicol region of the Philippines. - Economic Development and Cultural Change 34(4): 755-82.

[6] Akombi, B. J., Agho, K. E., Hall, J. J., Merom, D., Astell-Burt, T., Renzaho, A. M. (2017): Stunting and severe stunting among children under 5 years in Nigeria: a multilevel analysis. - BMC Pediatrics 17(1): 15.

[7] Alemayehu, M., Tinsae, F., Haileslassie, K., Seid, O., Gebregziabher, G., Yebyo, H. (2015): Under-nutrition status and associated factors in under-5 children, in Tigray, Northern Ethiopia. - Nutrition 31(7-8): 964-70.

[8] Altare, C., Delbiso, T. D., Mutwiri, G. M., Kopplow, R., Guha-Sapir, D. (2016): Factors associated with stunting among pre-school children in Southern highlands of Tanzania. Journal of Tropical Pediatrics 62(5): 390-408.

[9] Amugsi, D. A., Mittelmark, M. B., Lartey, A., Matanda, D. J., Urke, H. B. (2014): Influence of childcare practices on nutritional status of Ghanaian children: a regression analysis of the Ghana Demographic and Health Surveys. - BMJ Open 4(11): e005340.

[10] Anekwe, T. D., Kumar, S. (2012): The effect of a vaccination program on child anthropometry: evidence from India's Universal Immunization Program. - Journal of Public Health 34(4): 489-97.

[11] Anya, S. B., Yene, A. (2016): The determinants of the choice of treatment of pregnant women in Cameroon. - Health Economics Review 6(1): 48.

[12] Arif, G. M., Nazir, S., Satti, M. N. and Farooq, S. (2012): Child malnutrition in Pakistan: trends and determinants. - Pak Inst Dev Econ 2012: 1-18.

[13] Arooj, S., Ali, S., Baber, N., Abbasi, A., Ali, M. (2013): Socioeconomic factors effecting polio vaccination in Pakistan. - Health 5(5): 892.

[14] Asif, A. M., Tahir, M. R., Arshad, I. A., (2017): Socioeconomic condition and prevalence of malaria fever in Pakistani children: findings from a community health survey. Journal of Tropical Pediatrics 64(3): pp.189-194.

[15] Asena, T. F., Teni, D. A. (2015): Bayesian semi-parametric regression analysis of childhood under-nutrition in Gamo Gofa Zone: the social and economic impact of child under nutrition. - American Journal of Theoretical and Applied Statistics 4(4): 269-76. 
[16] Ben-Akiva, M. E., Lerman, S. R., Lerman, S. R. (1985): Discrete choice analysis: theory and application to travel demand. - MIT Press, Cambridge, MA.

[17] Breiman, L., Friedman, J. H., Olshen, R., Stone, C. (1984): Classification and Regression Trees. - Wadsworth, California.

[18] Checkley, W., Buckley, G., Gilman, R. H., Assis, A. M., Guerrant, R. L., Morris, S. S., Mølbak, K., Valentiner-Branth, P., Lanata, C. F., Black, R. E., Childhood Malnutrition and Infection Network (2008): Multi-country analysis of the effects of diarrhoea on childhood stunting. - International Journal of Epidemiology 37(4): 816-830.

[19] Chowdhury, M. R., Rahman, M. S., Khan, M. M., Mondal, M. N., Rahman, M. M., Billah, B. (2016): Risk factors for child under-nutrition in Bangladesh: a multilevel analysis of a nationwide population-based survey. - The Journal of Pediatrics 172: 194201.

[20] Darteh, E. K., Acquah, E., Kumi-Kyereme, A. (2014): Correlates of stunting among children in Ghana. - BMC Public Health 14(1): 504.

[21] Das, S., Bose, K. (2011): Assessment of nutritional status by anthropometric indices in Santal Tribal Children. - Journal of Life Sciences 3(2): 81-5.

[22] Dasgupta, A., Sahoo, S. K., Taraphdar, P., Preeti, P. S., Biswas, D., Kumar, A., Sarkar, I. (2015): Composite index of anthropometric failure and its important correlates: a study among under-5 children in a slum of Kolkata, West Bengal, India. - International Journal of Medical Science and Public Health 4(3): 414-20.

[23] Debnath, A., Bhattacharjee, N. (2016): Understanding under-nutrition of tribal children in India: the role of women's empowerment. - Ecology of Food and Nutrition 55(6): 50827.

[24] Ejaz, A. K. R., Azid, T. (2011): Under-nutrition in primary school-age children: a case of urban and slum areas of Bahawalpur, Pakistan. - International Journal of Social Economics 38(9): 748-66.

[25] Endris N., Asefa, H., Dube, L. (2017): Prevalence of under-nutrition and associated factors among children in rural Ethiopia. - BioMed Research International. DOI: $10.1108 / 03068291111157221$.

[26] Fentahun, N., Belachew, T., Lachat, C. (2016): Determinants and morbidities of multiple anthropometric deficits in southwest rural Ethiopia. - Nutrition 32(11-12): 1243-9.

[27] Final Report PDHS (2012-13): Pakistan Demographic and Health Survey. https://dhsprogram.com/publications/publication-fr290-dhs-final-reports.cfm.

[28] Fink, G., Günther, I., Hill, K. (2011): The effect of water and sanitation on child health: evidence from the demographic and health surveys 1986-2007. - International Journal of Epidemiology 40(5): 1196-204.

[29] Fleten, C., Nystad, W., Stigum, H., Skjærven, R., Lawlor, D. A., Davey Smith, G., Næss, $\varnothing$. (2012): Parent-offspring body mass index associations in the Norwegian Mother and Child Cohort Study: a family-based approach to studying the role of the intrauterine environment in childhood adiposity. - American Journal of Epidemiology 176(2): 83-92.

[30] Frongillo Jr, E. A., de Onis, M., Hanson, K. M. (1997): Socioeconomic and demographic factors are associated with worldwide patterns of stunting and wasting of children. - The Journal of Nutrition 127(12): 2302-9.

[31] Haidar, J., Kogi-Makau, W. (2009): Gender differences in the household-headship and nutritional status of pre-school children. - East African Medical Journal 86(2): 69-73.

[32] Hatt, L. E., Waters, H. R. (2006): Determinants of child morbidity in Latin America: a pooled analysis of interactions between parental education and economic status. - Social Science \& Medicine 62(2): 375-86.

[33] Hazarika, G. (2000): Gender differences in children's nutrition and access to health care in Pakistan. - The Journal of Development Studies 37(1): 73-92.

[34] Hu, W., Donnell, E. T. (2010): Median barrier crash severity: some new insights. Accident Analysis \& Prevention 42(6): 1697-704. 
[35] Jung, S. H., Chen, Y., Ahn, H. (2014): Type I error control for tree classification. Cancer Informatics 13: CIN-S16342.

[36] Kamiya, Y., Nomura, M., Ogino, H., Yoshikawa, K., Siengsounthone, L., Xangsayarath, P. (2018): Mothers' autonomy and childhood stunting: evidence from semi-urban communities in Lao PDR. - BMC Women's Health 18(1): 70.

[37] Kandala, N. B., Madungu, T. P., Emina, J. B., Nzita, K. P., Cappuccio, F. P. (2011): Under-nutrition among children under the age of five in the Democratic Republic of Congo (DRC): does geographic location matter? - BMC Public Health 11(1): 261.

[38] Khan, R. E., Raza, M. A. (2014): Child under-nutrition in developing economies: a case study of Bangladesh. - Quality \& Quantity 48(3): 1389-408.

[39] Kitsantas, P., Moore, T. W., Sly, D. F. (2007): Using classification trees to profile adolescent smoking behaviors. - Addictive Behaviors 32(1): 9-23.

[40] Krishna, A., Mejía-Guevara, I., McGovern, M., Aguayo, V., Subramanian, S. V. (2017): Trends in inequalities in child stunting in South Asia. - Maternal \& Child Nutrition e12517.

[41] Mahmood, S., Nadeem, S., Saif, T., Mannan, M., Arshad, U. (2016): Nutritional status and associated factors in under-five children of Rawalpindi. - Journal of Ayub Medical College Abbottabad 28(1): 67-71.

[42] Maïga, E. W. (2013): The impact of mother's education on child health and nutrition in developing countries: evidence from a natural experiment in Burkina Faso. - African Economic Conference 2013, 28-30 October, Johannesburg, South Africa.

[43] Marshall, R. J. (2001): The use of classification and regression trees in clinical epidemiology. - Journal of Clinical Epidemiology 54(6): 603-9.

[44] McFadden, D. (1981): Econometric Models of Probabilistic Choice. Structural Analysis of Discrete Data with Econometric Applications. - In: Manski, C., McFadden, D. (eds.) Structural Analysis of Discrete Data with Econometric Applications. MIT Press, Cambridge, pp. 198-272.

[45] Mushtaq, M. U., Gull, S., Khurshid, U., Shahid, U., Shad, M. A., Siddiqui, A. M. (2011): Prevalence and socio-demographic correlates of stunting and thinness among Pakistani primary school children. - BMC Public Health 11(1): 790.

[46] Nandy, S., Irving, M., Gordon, D., Subramanian, S. V., Smith, G. D. (2005): Poverty, child under-nutrition and morbidity: new evidence from India. - Bulletin of the World Health Organization 83: 210-6.

[47] Pawloski, L. R., Kitsantas, P. (2008): Classification tree analysis of stunting in Malian adolescent girls. - American Journal of Human Biology: The Official Journal of the Human Biology Association 20(3): 285-91.

[48] Petrou, S., Kupek, E. (2010): Poverty and childhood under-nutrition in developing countries: a multi-national cohort study. - Social Science \& Medicine 71(7): 1366-73.

[49] Poda, G. G., Hsu, C. Y., Chao, J. C. (2017): Factors associated with under-nutrition among children $<5$ years old in Burkina Faso: evidence from the Demographic and Health Surveys IV 2010. - International Journal for Quality in Health Care 29(7): 901-8.

[50] Pradhan, A. (2010): Factors associated with nutritional status of the under-five children. Asian Journal of Medical Sciences 1(1): 6-8.

[51] Rahman, A. (2016): Significant risk factors for childhood under-nutrition: evidence from an Asian developing country. - Science Journal of Public Health 4(1-1): 16-27.

[52] Rahman, M. M., Saima, U., Goni, M. A. (2015): Impact of maternal household decisionmaking autonomy on child nutritional status in Bangladesh. - Asia Pacific Journal of Public Health 27(5): 509-20.

[53] Raju, D., D'Souza, R. (2017): Child Under-Nutrition in Pakistan: What Do We know? The World Bank, Washington, DC.

[54] Rakotomanana, H., Gates, G. E., Hildebr, D., Stoecker, B. J. (2017): Determinants of stunting in children under 5 years in Madagascar. - Maternal \& Child Nutrition 13(4): e12409. 
[55] Sarma, H., Khan, J. R., Asaduzzaman, M., Uddin, F., Tarannum, S., Hasan, M. M., Rahman, A. S., Ahmed, T. (2017): Factors influencing the prevalence of stunting among children aged below five years in Bangladesh. - Food and Nutrition Bulletin 38(3): 291301.

[56] Sen, J., Mondal, N. (2012): Socio-economic and demographic factors affecting the Composite Index of Anthropometric Failure (CIAF). - Annals OxF Human Biology 39(2): 129-36.

[57] Senbanjo, I. O., Olayiwola, I. O., Afolabi, W. A., Senbanjo, O. C. (2013): Maternal and child under-nutrition in rural and urban communities of Lagos state, Nigeria: the relationship and risk factors. - BMC Research Notes 6(1): 286.

[58] Sharma, A., Kader, M. (2013): Effect of women's decision-making autonomy on infant's birth weight in rural Bangladesh. - ISRN Pediatrics. DOI: 10.1155/2013/159542.

[59] Solanki, R., Patel, T., Shah, H., Singh, U. S. (2014): Measuring under-nutrition through z-scores and Composite Index of Anthropometric Failure (CIAF): a study among slum children in Ahmedabad City, Gujarat. - National Journal of Community Medicine 5(4): 434-9.

[60] Svedberg, P. (2000): Poverty and Under-Nutrition: Theory, Measurement, and Policy. Clarendon Press, Oxford, UK.

[61] Tariq, J., Sajjad, A., Zakar, R., Zakar, M. Z., Fischer, F. (2018): Factors associated with under-nutrition in children under the age of two years: secondary data analysis based on the Pakistan Demographic and Health Survey 2012-2013. - Nutrients 10(6): 676.

[62] Tigga, P. L., Sen, J. (2016): Maternal body mass index is strongly associated with children-scores for height and BMI. - Journal of Anthropology. http://dx.doi.org/10.1155/2016/6538235.

[63] Toyama, N., Wakai, S., Nakamura, Y., Arifin, A. (2001): Mother's working status and nutritional status of children under the age of 5 in urban low-income community, Surabaya, Indonesia. - Journal of Tropical Pediatrics 47(3): 179-81.

[64] United Nations Children's Fund (1990): Strategy for Improved Nutrition of Children and Women in Developing Countries. A UNICEF Policy Review. - ERIC Clearinghouse, New York.

[65] Vikram, K., Vanneman, R., Desai, S. (2012): Linkages between maternal education and childhood immunization in India. - Social Science Medicine 75(2): 331-9.

[66] World Health Organization (2017): UNICEF-WHO-The World Bank: Joint Child UnderNutrition Estimates. - https://www.who.int/nutgrowthdb/estimates/en.

\section{APPENDIX}

Table A1. Descriptions of explanatory variables

\begin{tabular}{c|c}
\hline Variables & Categories (zero is the reference category) \\
\hline Region & Punjab $=0$, Sindh $=1, \mathrm{KPK}=2$, Blochistan $=3, \mathrm{~GB}=4$, Islamabad $=5$ \\
Urban $=0$, Rural $=1$ \\
Male $=0$, Female $=1$ \\
Gender & Poor $=0$, Middle $=1$, Rich $=2$ \\
Wealth status & No $=0$, Yes $=1$ \\
Mother's education & No-education $=0$, Primary $=1$, Secondary $=2$, Higher \& Above $=3$ \\
Working mother & Normal $=0$, Underweight $=1$, Overweight $=2$ \\
Mother's BMI & No-autonomy $=0$, Partial-autonomy $=1$, Full-autonomy $=2$ \\
Mother's autonomy & No $=0$, Yes $=1$ \\
Diarrhea & Not-vaccinated $=0$, Partially-vaccinated $=1$, Fully-vaccinated $=2$ \\
Vaccination & Male $=0$, Female $=1$ \\
Sex of household head & High-quality $=0$, Medium-quality $=1$, poor-quality $=2$ \\
Type of toilet &
\end{tabular}


Figure A1. Map showing different regions

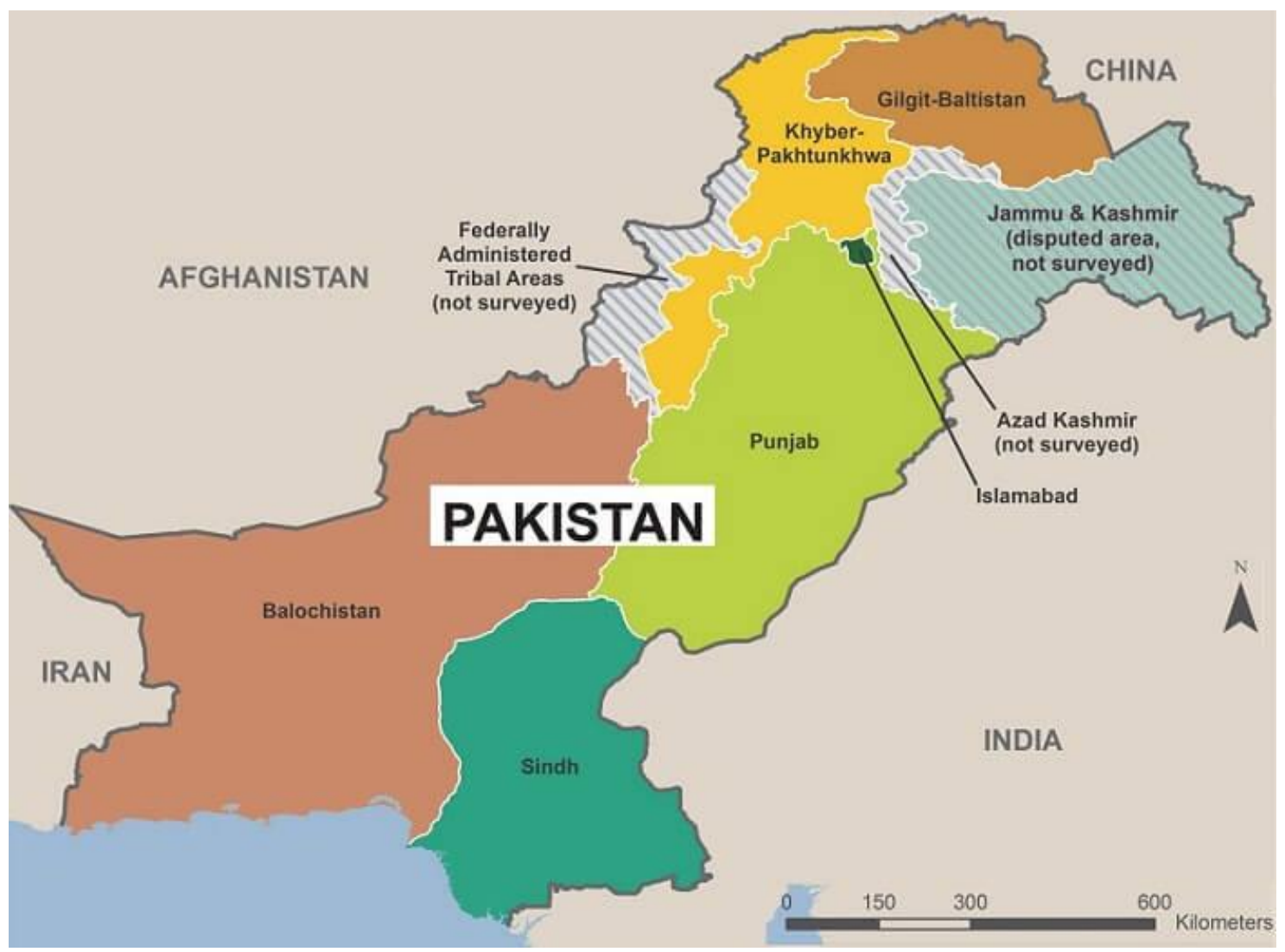

Figure A2. Interactions for mother's education, wealth status and mother's body mass index

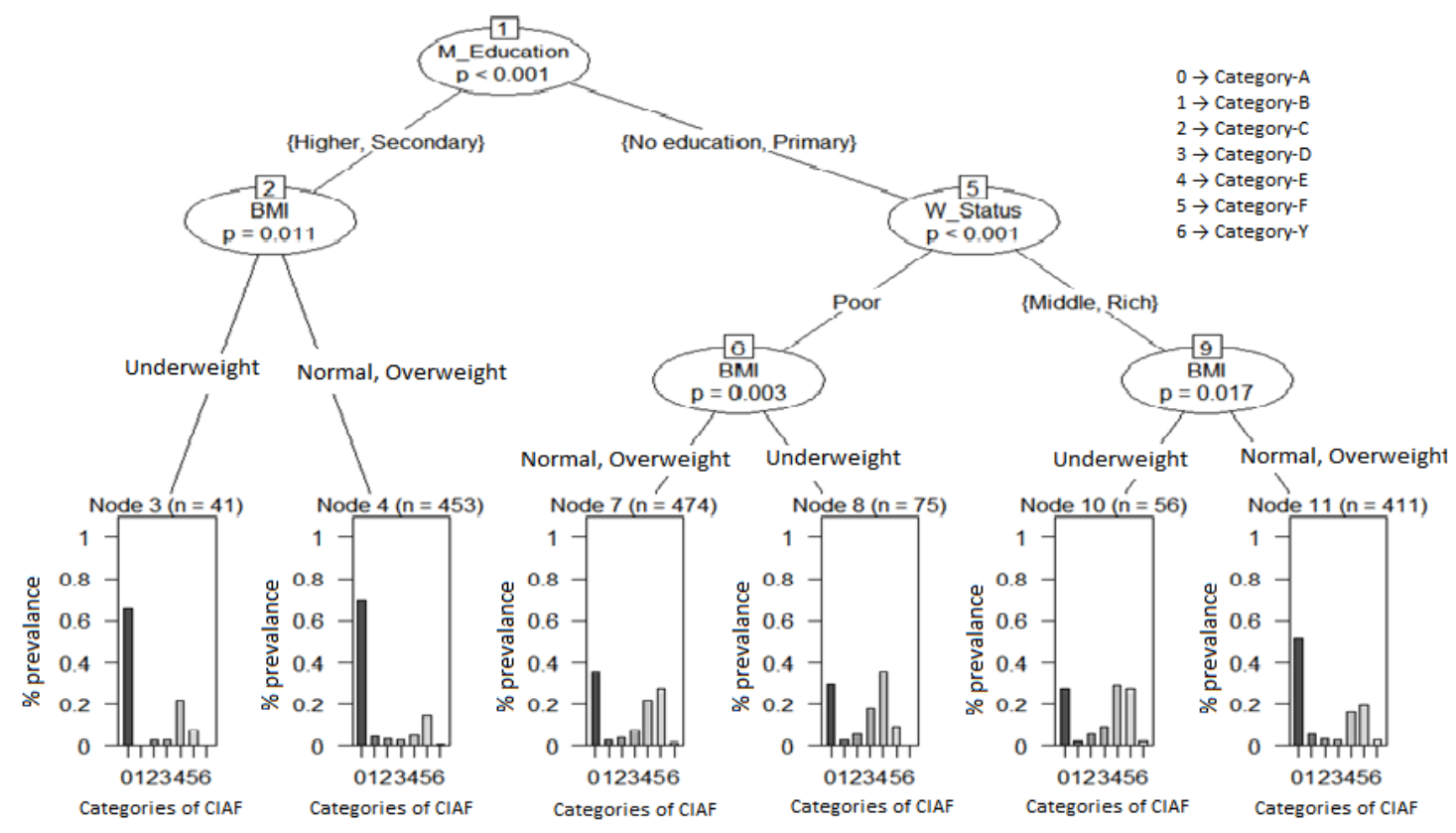


Figure A3. Interactions for mother's education and mother's working status

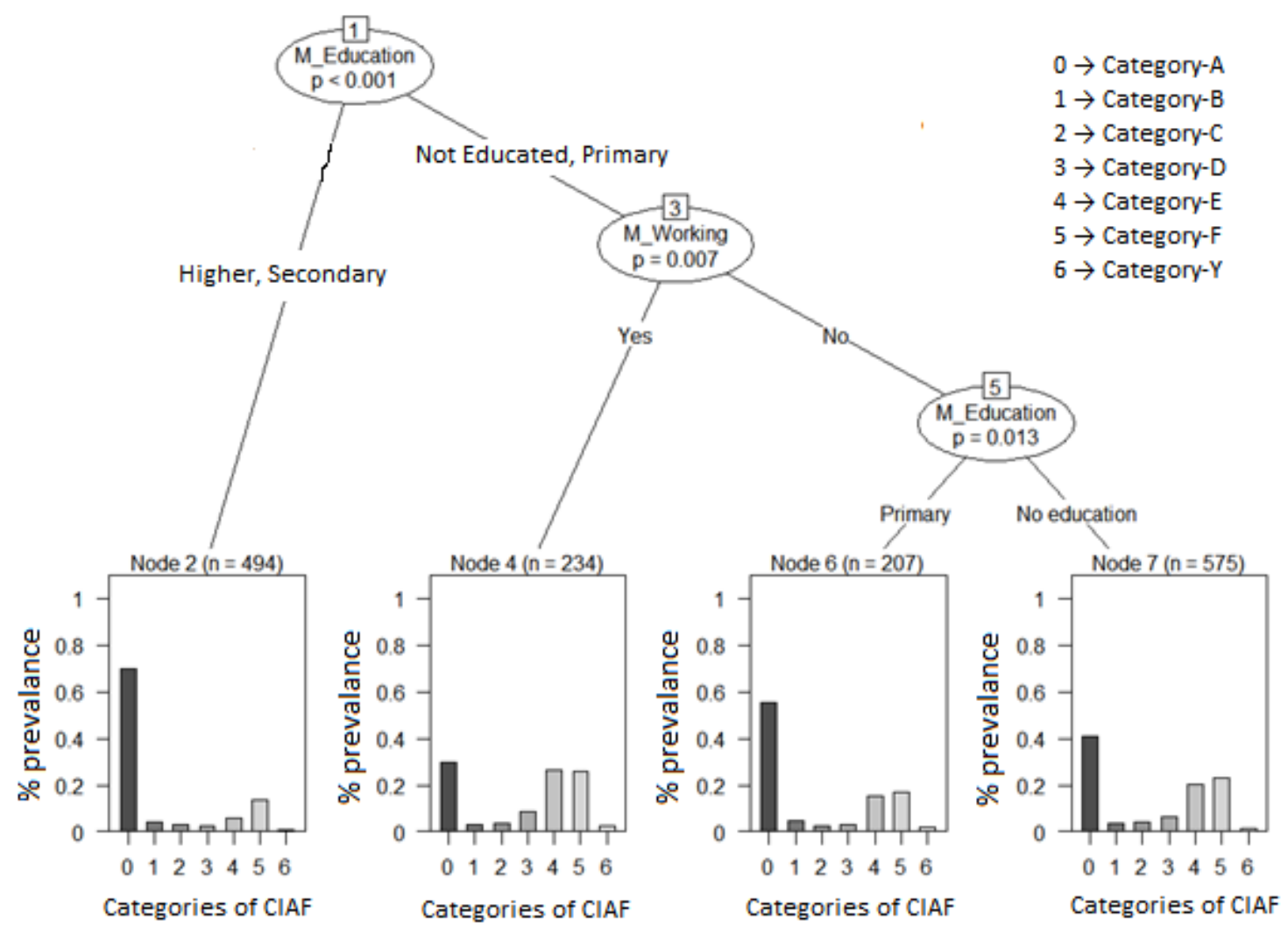

